\title{
a6-Containing Nicotinic Acetylcholine Receptors Dominate the Nicotine Control of Dopamine Neurotransmission in Nucleus Accumbens
}

\author{
Richard Exley', Michael A Clements ${ }^{1,2}$, Henrike Hartung ${ }^{2}$, J Michael McIntosh ${ }^{3}$ and Stephanie J Cragg*,' \\ 'Department of Physiology, Anatomy and Genetics, University of Oxford, Oxford, UK; ${ }^{2}$ University Department of Pharmacology, University of \\ Oxford, Oxford, UK; ${ }^{3}$ Departments of Biology and Psychiatry, University of Utah, Salt Lake City, UT, USA
}

\begin{abstract}
Modulation of striatal dopamine (DA) neurotransmission plays a fundamental role in the reinforcing and ultimately addictive effects of nicotine. Nicotine, by desensitizing $\beta 2$ subunit-containing $(\beta 2 *)$ nicotinic acetylcholine receptors (nAChRs) on striatal DA axons, significantly enhances how DA is released by reward-related burst activity compared to nonreward-related tonic activity. This action provides a synaptic mechanism for nicotine to facilitate the DA-dependent reinforcement. The subfamily of $\beta 2 *$-nAChRs responsible for these potent synaptic effects could offer a molecular target for therapeutic strategies in nicotine addiction. We explored the role of $\alpha 6 \beta 2 *$-nAChRs in the nucleus accumbens (NAc) and caudate-putamen (CPu) by observing action potential-dependent DA release from synapses in real-time using fast-scan cyclic voltammetry at carbon-fiber microelectrodes in mouse striatal slices. The $\alpha 6$-specific antagonist $\alpha$-conotoxin-MII suppressed DA release evoked by single and low-frequency action potentials and concurrently enhanced release by high-frequency bursts in a manner similar to the $\beta 2 *$-selective antagonist dihydro- $\beta$-erythroidine (DH $\beta \mathrm{E})$ in NAc, but less so in CPu. The greater role for $\alpha 6$ *-nAChRs in NAc was not due to any confounding regional difference in ACh tone since elevated ACh levels (after the acetylcholinesterase inhibitor ambenonium) had similar outcomes in NAc and CPu. Rather, there appear to be underlying differences in nAChR subtype function in NAc and CPu. In summary, we reveal that $\alpha 6 \beta 2 *$-nAChRs dominate the effects of nicotine on DA release in NAc, whereas in CPu their role is minor alongside other $\beta 2 *$-nAChRs (eg $\alpha 4 *$ ), These data offer new insights to suggest striatal $\alpha 6 *$-nAChRs as a molecular target for a therapeutic strategy for nicotine addiction.

Neuropsychopharmacology (2008) 33, 2158-2166; doi:10.1038/sj.npp.1301617; published online 21 November 2007
\end{abstract}

Keywords: addiction; smoking; striatum; $\alpha$-conotoxin-MIl; dopamine release; cholinergic interneurons

\section{INTRODUCTION}

Striatal dopamine (DA) neurotransmission plays key roles in signaling information about natural as well as artificial reinforcers like addictive drugs (including nicotine) (Corrigall et al, 1992; Imperato et al, 1986; Nisell et al, 1994; Schultz, 2002; Wise, 2004). In particular, mesostriatal dopaminergic neurons signal reward-predicting stimuli and receipt of unpredicted rewards by brief bursts of high-frequency neuron activity (Schultz, 1986, 2002). Striatal nicotinic acetylcholine receptors (nAChRs) operate a powerful and complex neuromodulatory control over the dynamic probability of DA release during such bursts as well as non-burst activity (Rice and Cragg, 2004; Zhang and Sulzer, 2004; Zhou et al, 2001). Tonic levels of striatal $\mathrm{ACh}$ at $\beta 2$-subunit-containing $\left(\beta 2^{*}\right)$-nAChRs promote DA

*Correspondence: Dr S Cragg, Department of Physiology, Anatomy and Genetics, Sherrington Building, University of Oxford, Oxford OXI 3PT, UK, Tel: + 44 I865 282513, Fax: + 441865272469 ,

E-mail: Stephanie.cragg@dpag.ox.ac.uk

Received II May 2007; revised 9 August 2007; accepted 29 September 2007 release by individual action potentials but, owing to accompanying short-term synaptic depression, minimize the release of DA by subsequent action potentials in highfrequency bursts (Cragg, 2006; Rice and Cragg, 2004). Nicotine, at concentrations seen in smokers, desensitizes tonically active $\beta 2^{*}$-nAChRs (Mansvelder et al, 2002; Pidoplichko et al, 1997); in striatum, this reduces initial DA release probability, removes short-term depression and consequently facilitates release by bursts (Rice and Cragg, 2004; Zhang and Sulzer, 2004; Zhou et al, 2001).

Nicotine also has effects at the somatodendritic level on DA neurons and inputs. Through a complex activation and desensitization of $\alpha 7$ and $\beta 2^{\star}$-nAChRs respectively in midbrain, nicotine increases DA neuron excitability (see Grenhoff et al, 1986; Mansvelder et al, 2002; Schilstrom et al, 2003). Together these somatodendritic and axonal actions offer a two-step mechanism (Exley and Cragg, in press) through which nicotine can promote how burst activity in DA neurons facilitates DA-dependent reinforcement processing that ultimately contributes to addiction.

The neurochemical as well as corresponding reinforcing effects of nicotine depend critically on $\beta 2^{*}$-nAChRs (Picciotto et al, 1998). However, $\beta 2^{\star}$-nAChRs comprise a 
diverse family expressed widely throughout the brain. The identity of the corresponding $\alpha$-subunits of the specific nAChRs that participate in the effects of nicotine within striatum are unresolved. Rodent striatal DA axon terminals contain $\beta 2$ subunits coexpressed predominantly with $\alpha 4$, or $\alpha 6, \alpha 5$ and also $\beta 3$ subunits within at least three types of heteromeric pentamers, including $\alpha 4 \beta 2, \alpha 6 \beta 2 \beta 3$, and $\alpha 6 \alpha 4 \beta 2 \beta 3$ (Champtiaux et al, 2003; Charpantier et al, 1998; Cui et al, 2003; Exley and Cragg, in press; Grady et al, 2002; Klink et al, 2001; Quik and McIntosh, 2006; Quik et al, 2005; Salminen et al, 2004; Zoli et al, 2002). Unlike other subunits, expression of the $\alpha 6$ subunit is relatively restricted to catecholaminergic (and some visual system) neurons (Le Novere et al, 1996; Quik et al, 2001, 2002). Moreover, after somatic expression of $\alpha 6$ mRNA in VTA/SN DA neurons (Azam et al, 2002, 2007), plasmamembrane $\alpha 6^{*}$-nAChRs on DA axon terminals (Quik et al, 2002; Zoli et al, 2002) may account for up to $40 \%$ of $\beta 2^{\star}$-nAChRs (in rat) (Zoli et al, 2002). Given their restricted localization to striatal DA axons, $\alpha 6^{*}$-nAChRs are attracting attention as promising targets for selective pharmacotherapies in dopaminergic disorders including nicotine addiction and Parkinson's disease (Quik and McIntosh, 2006).

Here, by detecting dopamine release in real time using fastscan cyclic voltammetry (FCV) at carbon-fiber microelectrodes in striatal slices, we explored directly the role of striatal $\alpha 6 \beta 2^{\star}$-nAChRs in the dynamic control by endogenous ACh and nicotine of DA release probability during burst and nonburst activity. We reveal a role for $\alpha 6 \beta 2^{\star}$-nAChRs in the dynamic control of striatal DA release probability that differs markedly between the NAc and $\mathrm{CPu}$ to which different aspects of motivational and sensorimotor function are attributed.

\section{MATERIALS AND METHODS}

\section{Slice Preparation and Voltammetry}

Coronal striatal slices, $300 \mu \mathrm{m}$ thick, containing both nucleus accumbens $(\mathrm{NAc})$ and caudato-putamen $(\mathrm{CPu})$ were prepared from brains of C57/Bl6j mice (20-30 g; Charles River UK) using previously described methods (Cragg, 2003; Rice and Cragg, 2004). Extracellular DA concentration ([DA $]_{\mathrm{o}}$ ) was monitored at $32^{\circ} \mathrm{C}$ in bicarbonate-buffered artificial cerebrospinal fluid (containing $2.4 \mathrm{mM} \mathrm{Ca}^{2+}$ ) using FCV with $7 \mu \mathrm{m}$ carbon-fiber microelectrodes (tip length $\sim 50-100 \mu \mathrm{m}$, fabricated in-house) and a Millar Voltammeter (PD Systems, UK) as described previously (Cragg, 2003; Rice and Cragg, 2004). In brief, the scanning voltage was a triangular waveform $(-0.7$ to $+1.3 \mathrm{~V}$ range vs $\mathrm{Ag} / \mathrm{AgCl}$ ) at a scan rate of $800 \mathrm{~V} / \mathrm{s}$ and sampling frequency of $8 \mathrm{~Hz}$. The evoked current signal was attributed to DA by comparison of the potentials for peak oxidation and reduction currents with those of DA in calibration media ( + 500-600 and $-200 \mathrm{mV} v s \mathrm{Ag} / \mathrm{AgCl}$, respectively). Electrodes were calibrated in 1-2 $\mu \mathrm{M}$ DA in experimental media.

\section{Electrical Stimulation}

DA release was evoked by a surface, bipolar concentric electrode $(25 \mu \mathrm{m}$ diameter Pt/Ir; FHC, USA) $\sim 100 \mu \mathrm{m}$ from the recording electrode (Cragg, 2003; Cragg and Greenfield, 1997; Rice and Cragg, 2004). Stimulus pulses (200 $\mu$ s duration) were generated out-of-phase with FCV scans at currents $(0.5-0.7 \mathrm{~mA})$ that generate maximal DA release with a single pulse. Release is $\mathrm{Ca}^{2+}$-dependent and TTXsensitive (ie action potential-dependent) (Cragg, 2003; Cragg and Greenfield, 1997).

Evoked DA release on the timescale of these experiments is not modulated by glutamate or GABA at ionotropic receptors (Avshalumov et al, 2003; Cragg, 2003), or DA $\mathrm{D}_{2}$ receptors (Cragg, 2003). However, DA release is governed by a basal tone of endogenous $\mathrm{ACh}$ acting at presynaptic nAChRs on DA axons (Rice and Cragg, 2004; Zhang and Sulzer, 2004; Zhou et al, 2001). Local cholinergic interneurons in striatal slice preparations are spontaneously active as they are in vivo (Aosaki et al, 1994; Bennett and Wilson, 1999), and provide a dense network of ACh release sites (Contant et al, 1996; Descarries and Mechawar, 2000; Zhou et al, 2003) that can provide this background of endogenous ACh (Zhou et al, 2001). ACh release evoked by the stimulus does not appear to contribute to these effects: similar results were seen in pilot studies in parasagittal slices in which DA release was elicited by remote pathway stimulation (up to $1000 \mu \mathrm{m}$ ventrocaudal from the recording electrode) (Rice and Cragg, 2004).

\section{Experimental Design and Analysis}

Stimuli were repeated at 3-min intervals to ensure consistent release. Stimuli consisted of either single pulses (1 pulse, $p$ ) or bursts of pulses $(2-5 p)$ at a physiological range of DA neuron firing frequencies which included 'tonic' rates $(1-10 \mathrm{~Hz})$ and 'phasic' burst frequencies (25$100 \mathrm{~Hz}$ ) that mimic the firing patterns of DA neurons that accompany 'reward-related' events in vivo eg the presentation of primary reward, a conditioned reinforcer or rewardpredictor (Bayer and Glimcher, 2005; Hyland et al, 2002; Schultz, 1986). The term 'burst sensitivity' refers to the relative sensitivity of DA release to a burst $v s$ a single pulse and denotes the ratio of release by a $4 \mathrm{p}$ burst $v s 1 \mathrm{p}$.

Data are means \pm SEM and the sample size, $n$, is the number of observations. Number of animals in each data set is $\geqslant 3$. Comparisons for differences in means were assessed by one- or two-way ANOVA, post hoc multiple comparison $t$-tests (Bonferroni), or unpaired $t$-tests using GraphPad Prism. Curve fitting and linear regressions were performed in GraphPad Prism or SigmaPlot.

Recording sites were in the dorsal quartile of $\mathrm{CPu}$ or immediately ventral to the anterior commissure (NAC 'core'). Note that in NAc, a small population of recording sites $(\sim 20 \%)$ displayed only modest $\mathrm{nAChR}$ control of DA release (as revealed by the $\mathrm{nAChR}$ antagonist $\mathrm{DH} \beta \mathrm{E}$ ) and not the strong control seen more commonly. This observation may be consistent with immunocytochemical studies suggesting that the ventral striatum exhibits a heterogeneity of cholinergic innervation greater than in dorsal striatum (Phelps and Vaughn, 1986). Since the aim of the current study is to explore the role of the $\alpha 6$-subunit where nAChRs regulate DA release, data from this minority of recording sites were not included for analysis.

\section{Drugs}

$\alpha$-CtxMII was synthesized as described previously (Cartier et al, 1996). $\alpha$-CtxMII is a selective antagonist for 
$\alpha 3 / \alpha 6^{*}$-nAChRs (Cartier et al, 1996; Kuryatov et al, 2000), but since there is negligible presence of the $\alpha 3$-subunit in mouse striatum (Champtiaux et al, 2003; Zoli et al, 2002), $\alpha$-CtxMII is selective for $\alpha 6^{*}$-nAChRs (Champtiaux et al, 2002; Quik and McIntosh, 2006; Whiteaker et al, 2000). In the striatum, $\alpha$-CtxMII-sensitive $\alpha 6^{*}$-nAChRs include $\alpha 6 \beta 2 \beta 3$ and $\alpha 6 \alpha 4 \beta 2 \beta 3$-nAChRs (Salminen et al, 2004, 2005). The concentration of $\alpha$-CtxMII used here $(30 \mathrm{nM})$ has no reported detectable effects at non- $\alpha 6 / \alpha 3$-nAChRs (Cartier et al, 1996) and maximally inhibits the $\alpha$-CtxMII-sensitive component of nicotine-evoked $\left[{ }^{3} \mathrm{H}\right]$-DA release from striatal synaptosomes (Grady et al, 2002; McCallum et al, 2005; Salminen et al, 2004). Higher concentrations of $\alpha$-CtxMII $(100 \mathrm{nM})$ in this study had no additional effects (not illustrated). The effects of $\mathrm{DH} \beta \mathrm{E}$ were maximal at the concentrations used in this study $(100 \mathrm{nM}-1 \mu \mathrm{M})$ (data not illustrated). Ambenonium dichloride and $\alpha$-bungarotoxin were purchased from Tocris Bioscience (UK). All other reagents were purchased from Sigma-Aldrich (UK).

\section{RESULTS}

\section{Nicotine Gates DA Release Probability in CPu and NAc via $\beta 2^{\star}$-nAChRs}

In order to elucidate the role of striatal $\alpha 6^{*}$-nAChRs in the control of DA release by striatal ACh and nicotine, we first confirmed reported effects of nicotine on the dynamic properties of DA release probability in $\mathrm{CPu}$ and verified similar effects in NAc of the mouse. Nicotine (500 nM) desensitizes striatal nAChRs and thus reverses actions of endogenous striatal ACh (Rice and Cragg, 2004; Zhou et al, 2001). We used single stimulus pulses and bursts of pulses $(2-4 \mathrm{p}$ at $100 \mathrm{~Hz})$ to explore the dynamic regulation of DA release probability during bursts. These initial experiments used this intraburst frequency $(100 \mathrm{~Hz})$ which is at the uppermost range of frequencies observed in vivo, since this frequency most strongly reveals $\mathrm{nAChR}$ control in $\mathrm{CPu}$ (Rice and Cragg, 2004).

In control conditions, there was a limited greater sensitivity of DA release to multiple vs single pulses in $\mathrm{CPu}$ or NAc as previously described (Cragg, 2003; Rice and Cragg, 2004) eg a burst of $4 \mathrm{p}(100 \mathrm{~Hz})$ evoked only slightly but significantly greater $[\mathrm{DA}]_{\mathrm{o}}$ than a single pulse in $\mathrm{CPu}$ (Figure $1 \mathrm{a}$ and $\mathrm{b}$ ) and in NAc (Figure $1 \mathrm{c}$ and $\mathrm{d}$ ). Typically, ratios of $[\mathrm{DA}]_{\mathrm{o}}$ evoked by $4 \mathrm{p} v s 1 \mathrm{p}$ in $\mathrm{CPu}$ were $\sim 1.1$-fold $(\sim 2.3 v s \sim 2.0 \mu \mathrm{M})$, and in NAc were $\sim 1.3$-fold $(\sim 1.2 v s$ $\sim 1.6 \mu \mathrm{M})$. This limited difference in $[\mathrm{DA}]_{\mathrm{o}}$ evoked by burst $v s$ nonburst stimuli is characteristic of the short-term synaptic depression which rapidly occurs at striatal DA synapses and limits re-release at successive pulses within a burst (Cragg, 2003; Rice and Cragg, 2004). Nicotine $(500 \mathrm{nM})$ had significant effects on DA release probability in both $\mathrm{CPu}$ and $\mathrm{NAc:}[\mathrm{DA}]_{\mathrm{o}}$ evoked by $1 \mathrm{p}$ were
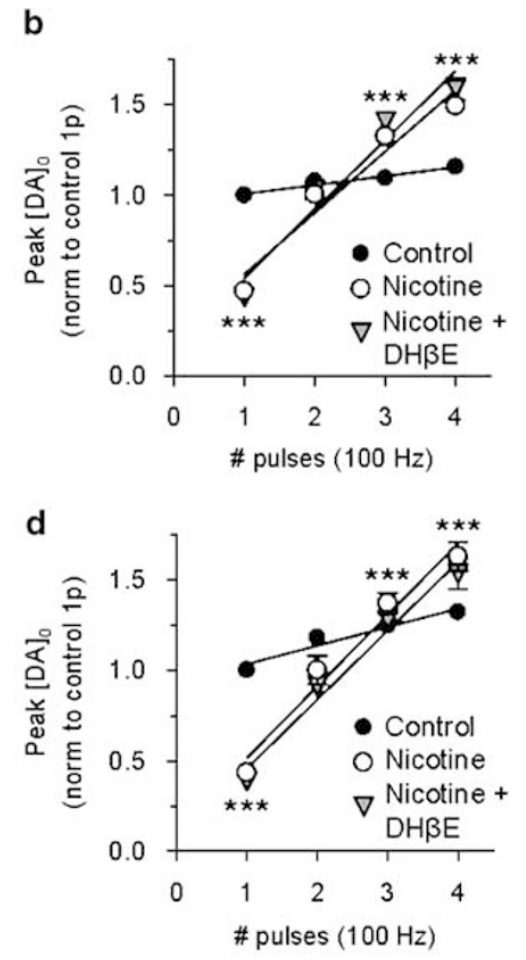

Figure I Nicotine gates striatal dopamine (DA) release probability in CPu and NAc via $\beta 2 *-n A C h R s$. (a, c) Averaged profiles of [DA]。 following stimuli (arrows) of $1-4$ pulses $(\mathrm{p})$ at $100 \mathrm{~Hz}$ in (left) control conditions, (center) nicotine ( $500 \mathrm{nM}$ ) or (right) nicotine plus DH $\beta E$ (I $00 \mathrm{nM})$ normalized to [DA]。 released by I $p$ in controls in (a) CPu and (c) NAc. One-way ANOVA for number of pulses, $* P<0.05$, **** $P<0.00$ I, $n=8-43$. (b, d) Mean peak [DA]。 \pm SEM vs number of pulses in a burst $(100 \mathrm{~Hz}$ ) in controls (filled circles), or nicotine (unfilled), or nicotine plus $\mathrm{DH} \beta \mathrm{E}$ (triangles) normalized to [DA]。 released by I $\mathrm{p}$ in controls in (b) CPu and (d) NAc. As previously in CPu after nAChR desensitization by nicotine (or nAChR block, (Rice and Cragg, 2004)), nicotine or nicotine plus $\mathrm{DH} \beta \mathrm{E}$ enhanced the sensitivity of DA release to pulse number (slope, or 'gain' increased to unity $\left(0.93-1.0 ; R^{2}>0.99\right)$, and enhanced the range of $[\mathrm{DA}]$ 。 in both (b) CPu and (d) NAc. Comparisons of linear regressions for control vs nicotine: $P<0.01, n=8-39$. Asterisks: Comparisons vs controls, post hoc Bonferroni t-tests, $* P<0.05$, $* * P<0.01$, **** $P<0.00$ I. Block of $n A C h R s$ by maximal $\mathrm{DH} \beta \mathrm{E}(\mathrm{I} 00 \mathrm{nM})$ was not additive upon $\mathrm{nAChR}$ desensitization by nicotine ( $n=8-1$ 8; Solid lines: linear regressions: $R^{2}>0.94$, nicotine not different to nicotine plus $\mathrm{DH} \beta \mathrm{E}$, comparison of linear regressions: $P>0.05$ ). 
significantly reduced to $\sim 45 \%$ in both $\mathrm{CPu}$ (Figure $1 \mathrm{a}$ and b) and NAc (Figure $1 \mathrm{c}$ and d). Correspondingly, the sensitivity of DA release to multiple pulses in a burst was significantly enhanced by nicotine in both $\mathrm{CPu}$ and NAc (Figure $1 \mathrm{~b}$ and $\mathrm{d}$ ) resulting in a significant enhancement compared to control of $[\mathrm{DA}]_{\mathrm{o}}$ evoked by $4 \mathrm{p}(100 \mathrm{~Hz})$ to $\sim 140 \%$ of control in $\mathrm{CPu}$ (Figure $1 \mathrm{a}$ and $\mathrm{b}$ ) and to $\sim 120 \%$ in NAc (Figure 1c and d). Thus, in the presence of nicotine, ratios of $[\mathrm{DA}]_{\mathrm{o}}$ released by $4 \mathrm{p}$ vs $1 \mathrm{p}$ were enhanced to approximately 3-4 in both $\mathrm{CPu}$ and NAc (ie linear response to pulse number) (Figure 1a-d). These observations are similar to previously documented effects of nicotine in $\mathrm{CPu}$ (Rice and Cragg, 2004), where nicotine acting through nAChR desensitization reduces initial release probability at a single pulse and consequently relieves short-term depression which permits enhanced release by successive pulses within a burst.

We and others have previously shown that these effects of nicotine are indistinguishable from those of the nAChR antagonist dihydro- $\beta$-erythroidine $(\mathrm{DH} \beta \mathrm{E})$ indicating that nicotine is acting via desensitization of endogenous $\mathrm{ACh}$ tone at nAChRs (Rice and Cragg, 2004; Zhou et al, 2001). In the current study, subsequent coapplication $\mathrm{DH} \beta \mathrm{E}$ (100 nм) in the continued presence of nicotine did not further modify $\mathrm{DA}$ release compared to nicotine alone in either $\mathrm{CPu}$ or NAc (Figure 1) confirming that these effects of nicotine are due to desensitization of the entire population of striatal $\beta 2^{*}$ nAChRs that were activated by striatal ACh.

\section{Dominant Role for $\alpha 6 \beta 2^{*}$-nAChRs in NAc but not $\mathrm{CPu}$}

To identify the role of striatal $\alpha 6$ subunits in the potent $\beta 2^{*}$ $\mathrm{nAChR}$ regulation of DA release in $\mathrm{CPu}$ and NAc, we used the $\alpha 6$-selective nAChR antagonist, $\alpha$-CtxMII (Champtiaux et al, 2002; Nicke et al, 2004; Whiteaker et al, 2000). DH $\beta \mathrm{E}$ was subsequently coapplied to compare the effects of antagonism of the whole $\beta 2^{\star}$-nAChR population upon which nicotine acts. We first explored the effects of $\alpha$-CtxMII on the regulation of release by 1 or $4 \mathrm{p}(100 \mathrm{~Hz}$ burst). In $\mathrm{CPu}$, in control conditions, $[\mathrm{DA}]_{\mathrm{o}}$ evoked by a 4-p burst was slightly but significantly greater than release by a single pulse (Figure 2a) as seen previously (Figure 1). Application of $\alpha$-CtxMII $(30 \mathrm{nM})$ to $\mathrm{CPu}$ modestly but significantly reduced $[\mathrm{DA}]_{\mathrm{o}}$ evoked by a single pulse and slightly reduced $[D A]_{o}$ evoked by $4 \mathrm{p} / 100 \mathrm{~Hz}$ (Figure $2 \mathrm{a}$ and b), thus slightly but significantly increasing the sensitivity of DA release to burst $v s$ nonburst stimuli compared to controls (Figure 2b). However, subsequent coapplication of $\mathrm{DH} \beta \mathrm{E}$ to $\mathrm{CPu}$ in the continued presence of $\alpha$-CtxMII significantly further reduced $[\mathrm{DA}]_{\mathrm{o}}$ evoked by $1 \mathrm{p}$ compared to $\alpha$-CtxMII and also enhanced $[\mathrm{DA}]_{\mathrm{o}}$ evoked by a $4 \mathrm{p} / 100 \mathrm{~Hz}$ burst compared to $\alpha$-CtxMII (and compared to
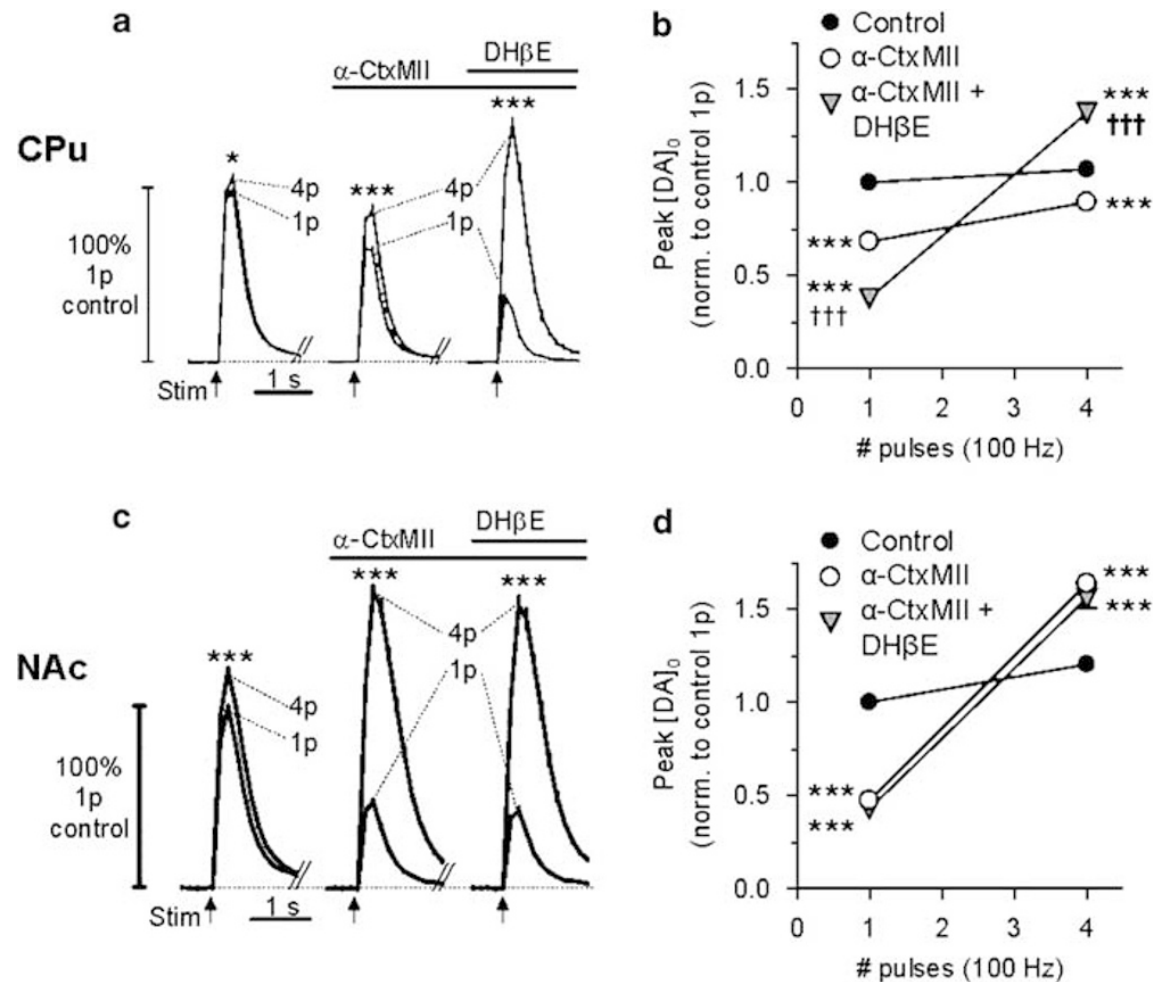

Figure $2 \alpha$-CtxMII reveals a dominant control of dopamine release by $\alpha 6 \beta 2$ *-nAChRs in NAc but not CPu. (a, c) Averaged profiles of [DA]。 following stimuli (arrows) of I or 4 pulses (p) at $100 \mathrm{~Hz}$ in (left) control conditions, (center) $\alpha$-CtxMII $(30 \mathrm{nM}$ ) or (right) $\alpha$-CtxMII plus DH $\beta$ E (I $\mu$ M) normalized to $[D A]$ 。 released by I $p$ in controls in (a) CPu and (c) NAc. One-way ANOVA for number of pulses, $* P<0.05, * * * P<0.001, n=\mid 8-63$. (b, d) Mean peak $[D A]_{\circ} \pm$ SEM vs number of pulses (I or $4 p, 100 \mathrm{~Hz}$ ) in controls (filled circles), $\alpha$-CtxMII (unfilled), or $\alpha$-CtxMll plus DH $\beta E$ (triangles) normalized to [DA]。 released by I $p$ in controls in (b) CPu and (d) NAc. Significance of post hoc $t$-tests indicated by asterisks for comparisons vs controls $(* P<0.05$, $* * * P<0.00$ I)

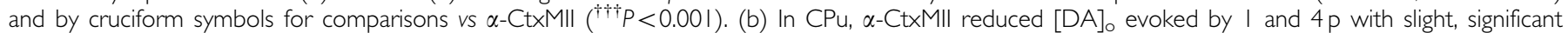
increase in sensitivity of DA release to number of pulses while addition of $\mathrm{DH} \beta \mathrm{E}$ further modified [DA]。 and sensitivity of $\mathrm{DA}$ release to a burst. $n=19-63$. (d) In NAc, $\alpha$-CtxMII significantly reduced I p release, enhanced burst release and enhanced sensitivity of DA release to number of pulses in a manner not modified further by $\mathrm{DH} \beta$ E. $n=16-52$. 
drug-free controls) (Figure $2 \mathrm{a}$ and $\mathrm{b}$ ). Thus, $\mathrm{DH} \beta \mathrm{E}$ dramatically promoted the relative sensitivity of DA release to a 4 -p burst $v s$ a single pulse compared to $\alpha$-CtxMII (Figure 2a and $\mathrm{b}$ ).

In NAc, in control conditions, $[D A]_{o}$ evoked by a $4-p$ burst $(100 \mathrm{~Hz})$ was slightly but significantly greater than release by a single pulse (Figure $2 \mathrm{c}$ and $\mathrm{d}$ ) as seen previously (Figure 1). Application of $\alpha$-CtxMII $(30 \mathrm{nM})$ to NAc significantly reduced $[\mathrm{DA}]_{\mathrm{o}}$ evoked by a single pulse and also increased $[D A]_{o}$ evoked by $4 \mathrm{p} / 100 \mathrm{~Hz}$ (Figure $2 \mathrm{c}$ and $\mathrm{d}$ ) thus enhancing the sensitivity of DA release to a burst compared to controls (Figure 2d). However, subsequent coapplication of $\mathrm{DH} \beta \mathrm{E}$ in the continued presence of $\alpha$-CtxMII did not further modify release by 1 or $4 p$ (Figure $2 c$ and d) or the relative sensitivity of DA release to each stimulus (Figure 2d).

In separate experiments, application of the selective $\alpha 7$ nAChR antagonist $\alpha$-bungarotoxin alone $(100 \mathrm{nM})$ did not modify $[D A]_{0}$ evoked by either a single pulse stimulation or a high-frequency burst (data not illustrated) indicating a lack of control of DA release by $\alpha 7^{\star}$-nAChRs.

\section{$\alpha 6 \beta 2^{*}$-nAChRs Can Account for All Frequency Filtering of DA Release by nAChRs in NAc but not CPu}

Changes in dopaminergic firing frequency within a burst are critical to the processing of reward-related information: Typically, low-frequency activity $(0.5-5 \mathrm{~Hz})$ is associated
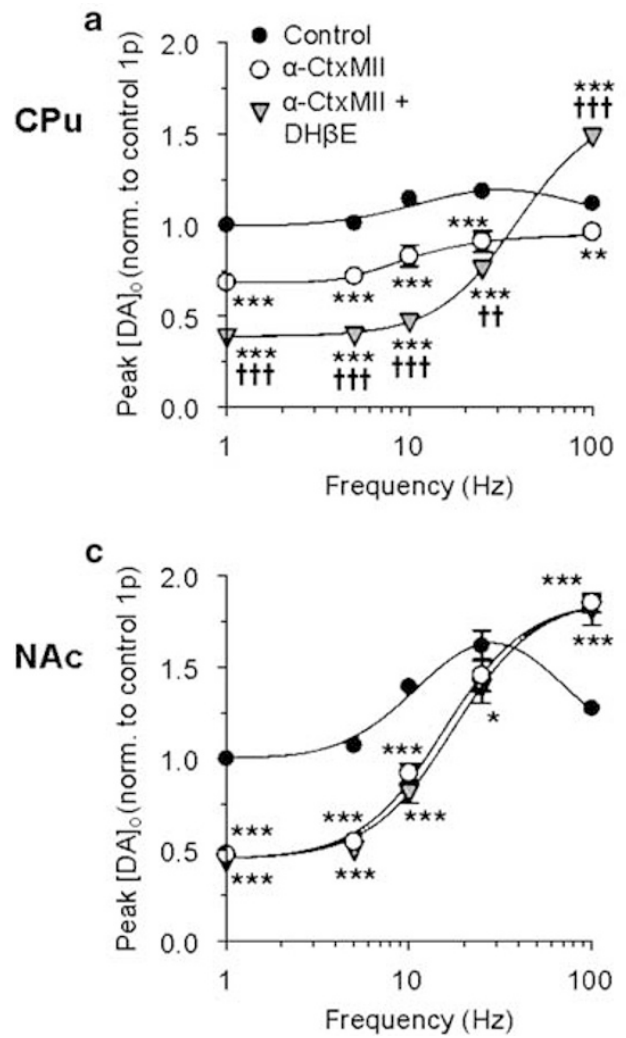

with nonreward-related activity, while high frequencies $(20-100 \mathrm{~Hz})$ signal reward-related information (Hyland et al, 2002; Schultz, 1986, 2002). We have previously shown that nAChRs critically govern how DA is released by different frequencies of presynaptic activity and that $\mathrm{nAChR}$ desensitization by nicotine changes this frequency filtering (Rice and Cragg, 2004; Zhang and Sulzer, 2004). By reducing DA release at low-frequency firing, and enhancing DA release at high-frequency firing, nicotine enhances the contrast in DA signals released by a different DA neuron frequency.

We explored the component role of $\alpha 6^{*}$-nAChRs in the regulation of DA signals evoked by reward-related frequencies $v s$ nonreward-related frequencies by using 5-p trains at frequencies ranging from 1 to $100 \mathrm{~Hz}$. In control conditions, $[D A]_{o}$ varied significantly with frequency according to a slight inverted U-relationship in both $\mathrm{CPu}$ (Figure $3 \mathrm{a}$ and $\mathrm{b}$ ) and NAc (Figure $3 \mathrm{c}$ and $\mathrm{d}$ ). In $\mathrm{CPu}$, the addition of $\alpha$-CtxMII slightly reduced $[\mathrm{DA}]_{\mathrm{o}}$ at all frequencies compared to control but also slightly enhanced the relationship between $[D A]_{o}$ and frequency (Figure $3 a$ and $b$ ). Specifically, the ratio of $[D A]_{0}$ released by $100 \mathrm{~Hz}$ compared to a single pulse was enhanced in the presence of $\alpha$-CtxMII compared to control (Figure $3 \mathrm{~b}$ ). However, subsequent coapplication of $\mathrm{DH} \beta \mathrm{E}$ in the continued presence of $\alpha$-CtxMII in $\mathrm{CPu}$ had additional frequency-specific effects. DH $\beta$ E reduced $[D A]_{0}$ evoked by low stimulation frequencies $(\leqslant 25 \mathrm{~Hz})$ but enhanced $[\mathrm{DA}]_{\mathrm{o}}$ evoked by higher frequencies $(>25 \mathrm{~Hz})$
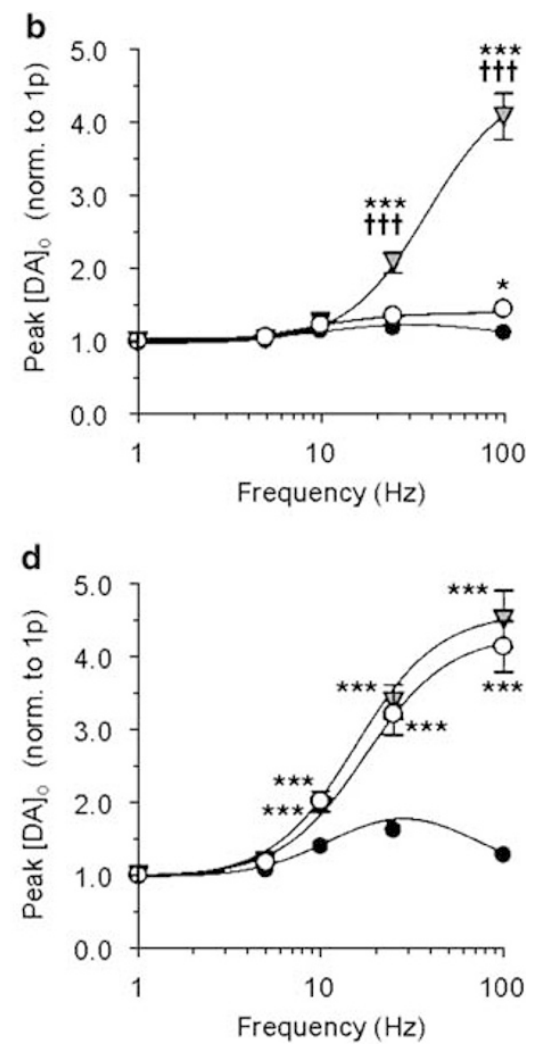

Figure $3 \alpha 6 \beta 2 *-n A C h R s$ can account for all frequency filtering of dopamine release by $n A C h R s$ in NAc but not CPu. (a-d) Mean peak [DA]。 \pm SEM vs frequency during 5 -pulse $(p)$ trains $(1-100 \mathrm{~Hz}$ ) in controls (filled circles), $\alpha$-CtxMII (unfilled), or $\alpha$-CtxMII plus DH $\beta E$ (triangles) normalized to [DA]。 released by $(a, c)$ I $p$ in controls or ( $b, d)$ I $p$ in each drug condition in $(a, b) C P u(n=12-63)$ and $(c, d) N A c(n=9-52)$. Significant effects of frequency: One-way ANOVAs $P<0.001$. Curve-fits in this frequency range are modified Gaussian (controls, $R^{2}>0.9$ ) or sigmoidal curves $\left(R^{2}>0.99\right)$. Significance of post hoc $t$-tests indicated by asterisks for comparisons vs controls (*P<0.05, **P<0.0I, ***P<0.00I) and by cruciform for comparisons of $D H \beta E$ vs $\alpha$-CtxMII $\left({ }^{\dagger \dagger} P<0.01,{ }^{\dagger \dagger} P<0.001\right)$. 
and thus enhanced the absolute concentration range (Figure 3a) as well as frequency-sensitive contrast (frequency sensitivity) of evoked $[\mathrm{DA}]_{\mathrm{o}}$ compared to $\alpha$-CtxMII and controls (Figure $3 b$ ).

In NAc by contrast, the addition of $\alpha$-CtxMII alone reduced $[\mathrm{DA}]_{\mathrm{o}}$ at low frequencies $(\leqslant 10 \mathrm{~Hz})$ compared to controls and increased $[\mathrm{DA}]_{\mathrm{o}}$ by frequencies $>25 \mathrm{~Hz}$ compared to controls (Figure $3 c$ and d). Thus, $\alpha$-CtxMII alone enhanced the absolute concentration range (Figure 3c) and frequency-sensitive contrast of evoked $[D A]_{o}$ in NAc compared to control (Figure 3d). In NAc, the addition of DH $\beta$ E to $\alpha$-CtxMII did not further modify [DA] or its frequency-dependence (Figure $3 c$ and $d$ ). Thus, selective block of $\alpha 6^{*}$-nAChRs antagonizes apparently all of the frequency-specific filtering effects of $\beta 2^{\star}$-nAChRs in $\mathrm{NAc}$, but only a partial component in $\mathrm{CPu}$.

Regional Differences in $\alpha 6-n A C h R$ Function Are Not due to Confounding Differences in Endogenous ACh Tone or DA Release Probability

These data suggest that striatal ACh and nicotine regulate DA release probability primarily via $\alpha 6 \beta 22^{*} \mathrm{nAChRs}$ in NAc, and via a more mixed population including non- $\alpha 6, \beta 2^{*}$ $\mathrm{nAChR}$ subtypes in $\mathrm{CPu}$. The greater role for $\alpha 6^{*}$-nAChRs in NAc could be due to a difference in the functional nAChRs present in axon terminals in $\mathrm{NAc}$ and $\mathrm{CPu}$. Alternatively, this functional difference could arise from an underlying similar receptor stoichiometry if there are differences in key driving forces eg ACh tone (or other factors contributing to DA release probability) in NAc and $\mathrm{CPu}$. For example, if ACh tone at striatal nAChRs (or DA release probability per se) were sufficiently higher in one region eg $\mathrm{CPu}$, then following selective blockade by $\alpha$-CtxMII of a subpopulation of nAChR receptors (ie $\alpha 6 \beta 2^{\star}$-nAChRs), cholinergic excitation at the remaining $\alpha$-CtxMII-resistant nAChRs (or depolarization due to other driving factors) may be sufficient to sustain DA release probability and thus mask any apparent influence of the $\alpha 6^{*}$ subpopulation.
In order to eliminate these confounding explanations, we first used the AChE inhibitor, ambenonium, to enhance extracellular ACh (Zhang et al, 2004) to test for different (lower) ACh tone in NAc vs CPu. Markers of striatal cholinergic innervation (choline acetyltransferase and AChE) show dense and patchy distributions within both dorsal and ventral striatum (Graybiel et al, 1986; Holt et al, 1997; Phelps and Vaughn, 1986; Zahm and Brog, 1992) but there is not a consensus from microdialysis reports for the comparative ACh tone (eg Ichikawa et al, 2002; Parada et al, 1997). However, ambenonium in striatum has been reported to increase single-pulse-evoked DA release at low concentrations $\left(\sim 10^{-9}-10^{-8} \mathrm{M}\right)$ but suppress DA release at higher concentrations $\left(>10^{-8} \mathrm{M}\right)$ when $\mathrm{ACh}$ reaches concentrations sufficient to desensitize nAChRs (Zhang et al, 2004). Thus, where $\mathrm{ACh}$ tone at $\mathrm{nAChRs}$ is highest, ambenonium (at higher concentrations) should more readily induce AChdependent $\mathrm{nAChR}$ desensitization. We explored DA release by a single pulse $(1 \mathrm{p})$ and by a 4 -p burst $(100 \mathrm{~Hz})$ in the presence of increasing concentrations of ambenonium $(0.1 \mathrm{nM}-10 \mu \mathrm{M})$. Ambenonium did not potentiate evoked $[\mathrm{DA}]_{\mathrm{o}}$ at any concentration in either $\mathrm{CPu}$ or $\mathrm{NAc}$, and concentration-dependently suppressed $[\mathrm{DA}]_{\mathrm{o}}$ evoked by $1 \mathrm{p}$ in a manner that was similar in $\mathrm{CPu}$ and NAc (Figure 4a). Suppression of $1 \mathrm{p}$ release by ambenonium in either region was accompanied by corresponding enhancements in the ratio of $[D A]_{o}$ evoked by burst $(4 \mathrm{p}, 100 \mathrm{~Hz}) \quad v s 1 \mathrm{p}$ in a similar manner in $\mathrm{CPu}$ and NAc (Figure 4a). These data suggest no underlying differences in $\mathrm{ACh}$ tone in NAc and $\mathrm{CPu}$.

Second, we compared whether other driving forces on release probability of DA differ between $\mathrm{CPu}$ and NAc by assessing the dependence of DA release evoked by a single pulse on stimulation current. Reductions in current (from $I=650$ to $35 \mu \mathrm{A}$ ) gradually reduced $[\mathrm{DA}]_{\mathrm{o}}$ to zero (or below limit of detection) and in a manner that was similar in $\mathrm{CPu}$ and NAc (Figure $4 \mathrm{~b}$ ). These data indicate that the greater role of $\alpha 6^{*}$-nAChRs in NAc is not due to differences in the net driving force on DA release probability. (Note that the absolute magnitude of effect of $\alpha 6^{*}$-nAChR antagonism
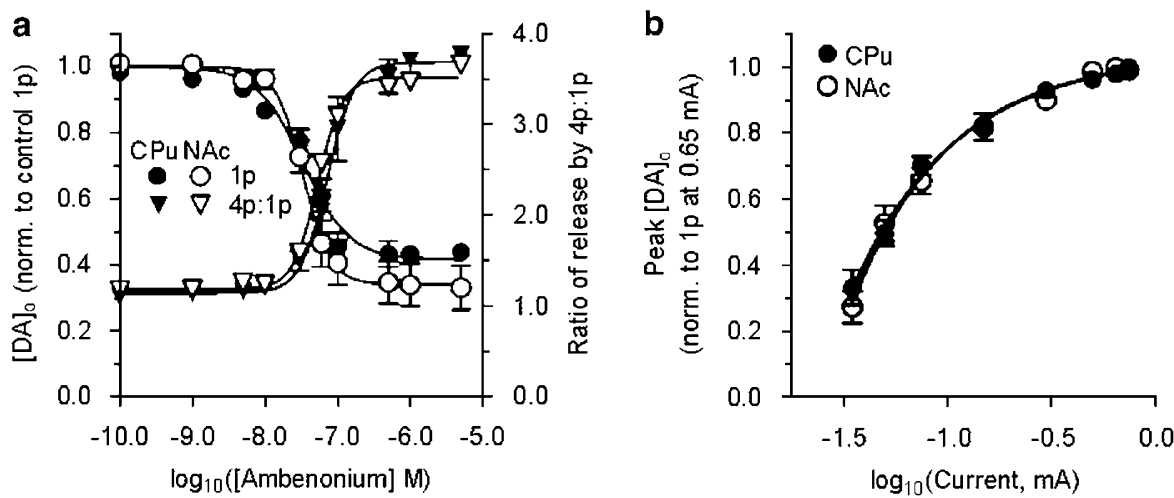

Figure 4 (a) No apparent variation in endogenous ACh tone and DA release probability in NAc vs CPu. Circles, Mean peak [DA]。 \pm SEM evoked by I $P$ as a function of concentration of the AChE inhibitor ambenonium in CPu (filled circles, $n=9$ ) and NAc (open circles, $n=9$ ). $[D A]$ 。 are normalized to control I p. Triangles, Corresponding covariation in ratio of release by a burst $(4 \mathrm{p}, 100 \mathrm{~Hz})$ vs a single pulse (right-hand y-axis) as a function of ambenonium concentration in CPu (filled) and NAc (unfilled). Curve-fits are sigmoidal $\left(R^{2}=0.8-0.98\right.$, maximum constrained to I00\%): For I $p$ data, curve-fits and IC ${ }_{50} \mathrm{~S}$ are not significantly different (32 nM, CPu; $34 \mathrm{nM}, \mathrm{NAc}$ ). (b) Mean peak [DA]。 \pm SEM evoked by I $p$ of varying stimulation current in CPu (filled circles, $n=||-98)$ and NAc (open circles, $n=|| \mid-100)$. [DA]。 are normalized to I p release at perimaximal stimulation current, $I_{\max }\left(I_{\max }=0.65 \mathrm{~mA}\right)$. Curve-fits are exponential rise to maximum $\left(R^{2}>0.99\right.$, maximum constrained to $100 \%$; comparison of curves: $\left.P<0.05\right)$. 
does however vary dynamically in both NAc and CPu with varying depolarizing conditions, see Supplementary Results and Supplementary Figures S1, S2.)

\section{DISCUSSION}

\section{$\beta 2^{\star}$-nAChRs Operate a Filter on DA Release Probability in $\mathrm{CPu}$ and $\mathrm{NAC}$}

At concentrations seen in the plasma of tobacco smokers, nicotine via desensitization of striatal $\beta 2^{\star}$-nAChRs (Zhou et al, 2001) enhances DA release in response to high frequency, reward-related bursts (Rice and Cragg, 2004; Zhang and Sulzer, 2004) and thus may enhance the 'salience' or processing of reward-related information. In the current study, we reveal that $\alpha 6 \beta 2^{*}$-nAChRs are the receptors most responsible for these effects in the NAc, but not in the $\mathrm{CPu}$. These data offer a potential cell-selective target for future therapy in nicotine addiction.

\section{Dominant Role for $\alpha 6$ Subunit in NAc but not $\mathrm{CPu}$}

The effects of the $\alpha 6^{*}$-nAChR antagonist, $\alpha$-CtxMII, revealed a function for $\alpha 6 \beta 2^{\star}$-nAChRs in the regulation of DA release by endogenous striatal $\mathrm{ACh}$ in $\mathrm{CPu}$ and $\mathrm{NAc}$, but with a striking dominance in the NAc. In $\mathrm{CPu}$, the effects of $\alpha$ CtxMII were a modest fraction of those seen with nicotine or the nAChR antagonist $\mathrm{DH} \beta \mathrm{E}$. $\alpha$-CtxMII slightly diminished DA release probability by single pulses, marginally relieved short-term depression during bursts, and correspondingly, only modestly enhanced the sensitivity of DA release to presynaptic frequency. In NAc by contrast, the effects of $\alpha$-CtxMII on DA release probability, and burst and frequency sensitivity were dramatic and indistinguishable from $\mathrm{DH} \beta \mathrm{E}$. These observations suggest that the $\beta 2^{*}$ nAChRs activated by endogenous ACh (and desensitized by nicotine) in $\mathrm{CPu}$ include a small population of $\alpha 6 \beta 2^{*}$ nAChRs and other non- $\alpha 6, \beta 2^{*}$-nAChR populations, whereas in NAc these receptors are predominantly $\alpha 6 \beta 2^{*}$ nAChRs.

The most simple explanation for the regional distinction in $\alpha 6^{*}$-nAChR function revealed here could be that a greater proportion of $\beta 2^{*}$-nAChRs activated by endogenous ACh (and desensitized by nicotine) contain the $\alpha 6$-subunit (ie $\alpha 4 \alpha 6 \beta 2 \beta 3$ - or $\alpha 6 \beta 2 \beta 3$-nAChRs) in NAc than CPu. We found no evidence for competing hypotheses that the more dominant role of $\alpha 6 \beta 2^{*}$-nAChRs in NAc could be otherwise explained by variations in ACh tone or in the sensitivity of DA axon membranes to depolarization. Thus, these functional differences most likely reflect a different stoichiometric composition of the nAChRs activated by endogenous $\mathrm{ACh}$ in striatum that regulate DA release and in turn, govern the effects of nicotine.

A function for $\alpha 6 \beta 2^{*}$-nAChRs is in keeping with ligand binding and immunoprecipitation studies that indicate that $\alpha 6$-subunits may exist in up to $40 \%$ of $\beta 2^{*}$-nAChRs in dopaminergic axon terminals in rat $\mathrm{CPu}$ (Zoli et al, 2002) including $\alpha 6 \beta 2 \beta 3$ or $\alpha 4 \alpha 6 \beta 2 \beta 3$ nAChRs (Champtiaux et al, 2003; Salminen et al, 2004; Zoli et al, 2002). Nicotine-evoked release of $\left[{ }^{3} \mathrm{H}\right]$-DA from rodent striatal synaptosomes and slices is also partially inhibited by $\alpha$-CtxMII (Champtiaux et al, 2003; Grady et al, 2002; Kaiser et al, 1998; Kulak et al,
1997; Salminen et al, 2004). However, work to date has not previously been able to address the striking functional dominance of $\alpha 6^{*}$-nAChRs in the control of DA release in NAc that we reveal here. For example, nAChR subunit expression data in the DA cell body regions (VTA and SNc) that give rise to ascending DA projections to NAc and $\mathrm{CPu}$ appears similar between cell groups (for non- $\alpha 7$ subunits) (Azam et al, 2002; Azam et al, 2007; Champtiaux et al, 2003; Klink et al, 2001; Wooltorton et al, 2003) and studies of nicotine-evoked $\left[{ }^{3} \mathrm{H}\right]$-DA release report a $\alpha$-CtxMII-sensitive fraction of release that is similar in synaptosomes derived from NAc or $\mathrm{CPu}$ (rodents: $40-55 \%$ (Champtiaux et al, 2003; Grady et al, 2002); monkeys: 70-80\% (McCallum et al, 2005)). However, differences between nicotine-evoked $\left[{ }^{3} \mathrm{H}\right]-\mathrm{DA}$ release studies and the physiological nAChR function identified in this study in an endogenous setting should be expected. Nicotine-evoked $\left[{ }^{3} \mathrm{H}\right]-D A$ release studies probe the nAChRs available to mediate an agonist secretagogue effect of nicotine on the release of exogenous DA; by contrast, our approach has unique access to the nAChRs that are tonically activated by physiological levels of endogenous $\mathrm{ACh}$, that regulate release probability of endogenous DA by action potentials and that will be desensitized by nicotine during smoking. Our data are the first to be able to reveal this dominance of $\alpha 6^{*}$-nAChR function in NAc. It does not however preclude the existence of non- $\alpha 6, \beta 2^{*}$-nAChRs in DA axons in NAc. Rather, it suggests that if populations of $\alpha$-CtxMII-insensitivenAChRs exist in DA axons in NAc, they are relatively redundant compared to $\alpha 6 \beta 2^{\star}$-nAChRs in the functional nAChR-regulation of action potential-evoked DA release.

While these regional differences primarily identify a $\mathrm{nAChR}$ that offers a potential means for differentially modifying ACh-DA and nicotine-DA interactions in ventral $v s$ dorsal striatum, it is possible that these data might also impact on how synchronized pauses in cholinergic neurons that occur in response to reward-related cues (Morris et al, 2004) govern DA function (Cragg, 2006). Differences (albeit currently unresolved) in affinity for ACh of each receptor type might have some impact on the efficacy or speed (and therefore time window) with which a fall and rise in striatal $\mathrm{ACh}$ tone at nAChRs would be detected and impact on striatal DA release following a synchronized pause in ACh neurons.

\section{SUMMARY AND CONCLUSIONS}

Striatal $\beta 2^{\star}$-nAChRs play a key role in the powerful effects of nicotine in governing how DA neuron activity is relayed in to DA release. Thus nicotine, via nAChR desensitization, can promote DA signaling by high frequency, rewardrelated activity (Rice and Cragg, 2004; Zhang and Sulzer, 2004) and thus participate in the signaling and learning of reward-related information which ultimately participates in nicotine dependence. The current data now indicate that $\alpha 6^{*}$-nAChRs play a key component function in this dynamic frequency filtering of DA release probability by endogenous $\mathrm{ACh}$ and nicotine. Furthermore, these data reveal for the first time that $\alpha 6^{*}$-nAChRs dominate in the effects of nicotine in the NAc. As a consequence, targeting of $\alpha 6 \beta 2^{*}$ or non- $\alpha 6 \beta 2^{*}$ nAChRs could differentially modulate the 
components of behavioral reinforcement and sensorimotor function with which ventral and dorsal striatum are differently associated. The discrete localization within the brain of $\alpha 6^{*}$-nAChRs to catecholaminergic neurons, in conjunction with these key distinctions in $\alpha 6^{*}-n A C h R$ control of DA neurotransmission between different DA systems, suggests that $\alpha 6^{*}$-nAChRs may offer a powerful molecular target for a highly selective future pharmacotherapeutic or genetic strategy to combat nicotine addiction.

\section{ACKNOWLEDGEMENTS}

We acknowledge support from the MJ Fox Foundation, the Parkinson's Disease Society (UK), the Biotechnology and Biological Sciences Research Council (UK), Eli Lilly UK, the Paton Fellowship (University of Oxford).

\section{DISCLOSURE/CONFLICTS OF INTEREST}

Dr Exley and H. Hartung report no biomedical financial interests or potential conflicts of interest. Dr McIntosh has been a consultant for and/or received funding from Cognetix, Pfizer, Metabolic, and GlaxoSmithKline. $\mathrm{M}$ Clements has received support and Dr Cragg research funding from Eli Lilly (UK).

\section{REFERENCES}

Aosaki T, Tsubokawa H, Ishida A, Watanabe K, Graybiel AM, Kimura M (1994). Responses of tonically active neurons in the primate's striatum undergo systematic changes during behavioral sensorimotor conditioning. J Neurosci 14: 3969-3984.

Avshalumov MV, Chen BT, Marshall SP, Pena DM, Rice ME (2003). Glutamate-dependent inhibition of dopamine release in striatum is mediated by a new diffusible messenger, H2O2. J Neurosci 23: 2744-2750.

Azam L, Chen Y, Leslie FM (2007). Developmental regulation of nicotinic acetylcholine receptors within midbrain dopamine neurons. Neuroscience 144: 1347-1360.

Azam L, Winzer-Serhan UH, Chen Y, Leslie FM (2002). Expression of neuronal nicotinic acetylcholine receptor subunit mRNAs within midbrain dopamine neurons. J Comp Neurol 444: 260-274.

Bayer HM, Glimcher PW (2005). Midbrain dopamine neurons encode a quantitative reward prediction error signal. Neuron 47: 129-141.

Bennett BD, Wilson CJ (1999). Spontaneous activity of neostriatal cholinergic interneurons in vitro. J Neurosci 19: 5586-5596.

Cartier GE, Yoshikami D, Gray WR, Luo S, Olivera BM, McIntosh JM (1996). A new alpha-conotoxin which targets alpha3beta2 nicotinic acetylcholine receptors. J Biol Chem 271: 7522-7528.

Champtiaux N, Gotti C, Cordero-Erausquin M, David DJ, Przybylski C, Lena C et al (2003). Subunit composition of functional nicotinic receptors in dopaminergic neurons investigated with knock-out mice. J Neurosci 23: 7820-7829.

Champtiaux N, Han ZY, Bessis A, Rossi FM, Zoli M, Marubio L et al (2002). Distribution and pharmacology of alpha 6-containing nicotinic acetylcholine receptors analyzed with mutant mice. J Neurosci 22: 1208-1217.

Charpantier E, Barneoud P, Moser P, Besnard F, Sgard F (1998). Nicotinic acetylcholine subunit mRNA expression in dopaminergic neurons of the rat substantia nigra and ventral tegmental area. Neuroreport 9: 3097-3101.
Contant C, Umbriaco D, Garcia S, Watkins KC, Descarries L (1996). Ultrastructural characterization of the acetylcholine innervation in adult rat neostriatum. Neuroscience 71: 937-947.

Corrigall WA, Franklin KB, Coen KM, Clarke PB (1992). The mesolimbic dopaminergic system is implicated in the reinforcing effects of nicotine. Psychopharmacology (Berl) 107: 285-289.

Cragg SJ (2003). Variable dopamine release probability and shortterm plasticity between functional domains of the primate striatum. J Neurosci 23: 4378-4385.

Cragg SJ (2006). Meaningful silences: how dopamine listens to the ACh pause. Trends Neurosci 29: 125-131.

Cragg SJ, Greenfield SA (1997). Differential autoreceptor control of somatodendritic and axon terminal dopamine release in substantia nigra, ventral tegmental area, and striatum. J Neurosci 17: $5738-5746$.

Cui C, Booker TK, Allen RS, Grady SR, Whiteaker P, Marks MJ et al (2003). The \{beta\} 3 nicotinic receptor subunit: a component of \{alpha\}-conotoxin MII-binding nicotinic acetylcholine receptors that modulate dopamine release and related behaviors. J Neurosci 23: 11045-11053.

Descarries L, Mechawar N (2000). Ultrastructural evidence for diffuse transmission by monoamine and acetylcholine neurons of the central nervous system. Prog Brain Res 125: 27-47.

Exley R, Cragg SJ (2007). Presynaptic nicotinic receptors: a dynamic and diverse cholinergic filter of striatal dopamine neurotransmission. Br J Pharmacol, in press.

Grady SR, Murphy KL, Cao J, Marks MJ, McIntosh JM, Collins AC (2002). Characterization of nicotinic agonist-induced [3H]dopamine release from synaptosomes prepared from four mouse brain regions. J Pharmacol Exp Ther 301: 651-660.

Graybiel AM, Baughman RW, Eckenstein F (1986). Cholinergic neuropil of the striatum observes striosomal boundaries. Nature 323: 625-627.

Grenhoff J, Aston-Jones G, Svensson TH (1986). Nicotinic effects on the firing pattern of midbrain dopamine neurons. Acta Physiol Scand 128: 351-358.

Holt DJ, Graybiel AM, Saper CB (1997). Neurochemical architecture of the human striatum. J Comp Neurol 384: 1-25.

Hyland BI, Reynolds JNJ, Hay J, Perk CG, Miller R (2002). Firing modes of midbrain dopamine cells in the freely moving rat. Neuroscience 114: 475-492.

Ichikawa J, Dai J, O’Laughlin IA, Fowler WL, Meltzer HY (2002). Atypical, but not typical, antipsychotic drugs increase cortical acetylcholine release without an effect in the nucleus accumbens or striatum. Neuropsychopharmacology 26: 325-339.

Imperato A, Mulas A, Di Chiara G (1986). Nicotine preferentially stimulates dopamine release in the limbic system of freely moving rats. Eur J Pharmacol 132: 337-338.

Kaiser SA, Soliakov L, Harvey SC, Luetje CW, Wonnacott S (1998). Differential inhibition by alpha-conotoxin-MII of the nicotinic stimulation of $[3 \mathrm{H}]$ dopamine release from rat striatal synaptosomes and slices. J Neurochem 70: 1069-1076.

Klink R, de Kerchove dA, Zoli M, Changeux JP (2001). Molecular and physiological diversity of nicotinic acetylcholine receptors in the midbrain dopaminergic nuclei. J Neurosci 21: 1452-1463.

Kulak JM, Nguyen TA, Olivera BM, McIntosh JM (1997). Alphaconotoxin MII blocks nicotine-stimulated dopamine release in rat striatal synaptosomes. J Neurosci 17: 5263-5270.

Kuryatov A, Olale F, Cooper J, Choi C, Lindstrom J (2000). Human [alpha]6 AChR subtypes: subunit composition, assembly, and pharmacological responses. Neuropharmacology 39: 2570-2590.

Le Novere N, Zoli M, Changeux JP (1996). Neuronal nicotinic receptor alpha 6 subunit mRNA is selectively concentrated in catecholaminergic nuclei of the rat brain. Eur J Neurosci 8: 2428-2439.

Mansvelder HD, Keath JR, McGehee DS (2002). Synaptic mechanisms underlie nicotine-induced excitability of brain reward areas. Neuron 33: 905-919. 
McCallum SE, Parameswaran N, Bordia T, McIntosh JM, Grady SR, Quik M (2005). Decrease in alpha3*/alpha6* nicotinic receptors but not nicotine-evoked dopamine release in monkey brain after nigrostriatal damage. Mol Pharmacol 68: 737-746.

Morris G, Arkadir D, Nevet A, Vaadia E, Bergman H (2004). Coincident but distinct messages of midbrain dopamine and striatal tonically active neurons. Neuron 43: 133-143.

Nicke A, Wonnacott S, Lewis RJ (2004). Alpha-conotoxins as tools for the elucidation of structure and function of neuronal nicotinic acetylcholine receptor subtypes. Eur J Biochem 271: 2305-2319.

Nisell M, Nomikos GG, Svensson TH (1994). Systemic nicotineinduced dopamine release in the rat nucleus accumbens is regulated by nicotinic receptors in the ventral tegmental area. Synapse 16: 36-44.

Parada MA, Hernandez L, Puig de PM, Rada P, Murzi E (1997). Selective action of acute systemic clozapine on acetylcholine release in the rat prefrontal cortex by reference to the nucleus accumbens and striatum. J Pharmacol Exp Ther 281: 582-588.

Phelps PE, Vaughn JE (1986). Immunocytochemical localization of choline acetyltransferase in rat ventral striatum: a light and electron microscopic study. J Neurocytol 15: 595-617.

Picciotto MR, Zoli M, Rimondini R, Lena C, Marubio LM, Pich EM et al (1998). Acetylcholine receptors containing the beta2 subunit are involved in the reinforcing properties of nicotine. Nature 391: 173-177.

Pidoplichko VI, DeBiasi M, Williams JT, Dani JA (1997). Nicotine activates and desensitizes midbrain dopamine neurons. Nature 390: 401-404.

Quik M, McIntosh JM (2006). Striatal alpha6* nicotinic acetylcholine receptors: potential targets for Parkinson's disease therapy. J Pharmacol Exp Ther 316: 481-489.

Quik M, Polonskaya Y, Kulak JM, McIntosh JM (2001). Vulnerability of 125I-\{alpha\}-conotoxin MII binding sites to nigrostriatal damage in monkey. J Neurosci 21: 5494-5500.

Quik M, Polonskaya Y, McIntosh JM, Kulak JM (2002). Differential nicotinic receptor expression in monkey basal ganglia: effects of nigrostriatal damage. Neuroscience 112: 619-630.

Quik M, Vailati S, Bordia T, Kulak JM, Fan H, McIntosh JM et al (2005). Subunit composition of nicotinic receptors in monkey striatum: effect of treatments with 1-methyl-4-phenyl-1,2,3, 6-tetrahydropyridine or L-DOPA. Mol Pharmacol 67: 32-41.

Rice ME, Cragg SJ (2004). Nicotine amplifies reward-related dopamine signals in striatum. Nat Neurosci 7: 583-584.

Salminen O, Murphy KL, McIntosh JM, Drago J, Marks MJ, Collins $\mathrm{AC}$ et al (2004). Subunit composition and pharmacology of two classes of striatal presynaptic nicotinic acetylcholine receptors mediating dopamine release in mice. Mol Pharmacol 65: $1526-1535$.

Salminen O, Whiteaker P, Grady SR, Collins AC, McIntosh JM, Marks MJ (2005). The subunit composition and pharmacology of alpha-Conotoxin MII-binding nicotinic acetylcholine receptors studied by a novel membrane-binding assay. Neuropharmacology 48: $696-705$.

Schilstrom B, Rawal N, Mameli-Engvall M, Nomikos GG, Svensson TH (2003). Dual effects of nicotine on dopamine neurons mediated by different nicotinic receptor subtypes. Int $J$ Neuropsychopharmacol 6: 1-11.

Schultz W (1986). Responses of midbrain dopamine neurons to behavioral trigger stimuli in the monkey. J Neurophysiol 56: 1439-1461.

Schultz W (2002). Getting formal with dopamine and reward. Neuron 36: 241-263.

Whiteaker P, McIntosh JM, Luo S, Collins AC, Marks MJ (2000). 125I-alpha-conotoxin MII identifies a novel nicotinic acetylcholine receptor population in mouse brain. Mol Pharmacol 57: 913-925.

Wise RA (2004). Dopamine, learning and motivation. Nat Rev Neurosci 5: 483-494.

Wooltorton JRA, Pidoplichko VI, Broide RS, Dani JA (2003). Differential desensitization and distribution of nicotinic acetylcholine receptor subtypes in midbrain dopamine areas. J Neurosci 23: 3176.

Zahm DS, Brog JS (1992). On the significance of subterritories in the 'accumbens' part of the rat ventral striatum. Neuroscience 50: 751-767.

Zhang H, Sulzer D (2004). Frequency-dependent modulation of dopamine release by nicotine. Nat Neurosci 7: 581-582.

Zhang L, Zhou FM, Dani JA (2004). Cholinergic drugs for Alzheimer's disease enhance in vitro dopamine release. Mol Pharmacol 66: 538-544.

Zhou FM, Liang Y, Dani JA (2001). Endogenous nicotinic cholinergic activity regulates dopamine release in the striatum. Nat Neurosci 4: 1224-1229.

Zhou FM, Wilson CJ, Dani JA (2003). Muscarinic and nicotinic cholinergic mechanisms in the mesostriatal dopamine systems. Neuroscientist 9: 23-36.

Zoli M, Moretti M, Zanardi A, McIntosh JM, Clementi F, Gotti C (2002). Identification of the nicotinic receptor subtypes expressed on dopaminergic terminals in the rat striatum. J Neurosci 22: 8785-8789.

Supplementary Information accompanies the paper on the Neuropsychopharmacology website (http://www.nature.com/npp) 